to use this for further estimations of the individual acids. acids, added in known quantities to the cheese mush, led to doubt as to whether this method of distillation resulted in the complete extraction of the volatile acids (especially the higher members of the series) from the cheese. It appeared that the higher acids were to some extent held back by the constituents of the cheese, and did not therefore distil over at the rate suggested by Dyer's figures ${ }^{1}$.

This view was strengthened by a series of experiments in which several acids were distilled from water, and a mixture of fresh, washed butter fat and water. It was evident that there was retention of for lauric acid and high for caprylic, but decreasing through caproic to butyric and the lower members of the series, in which no retention was demonstrated.

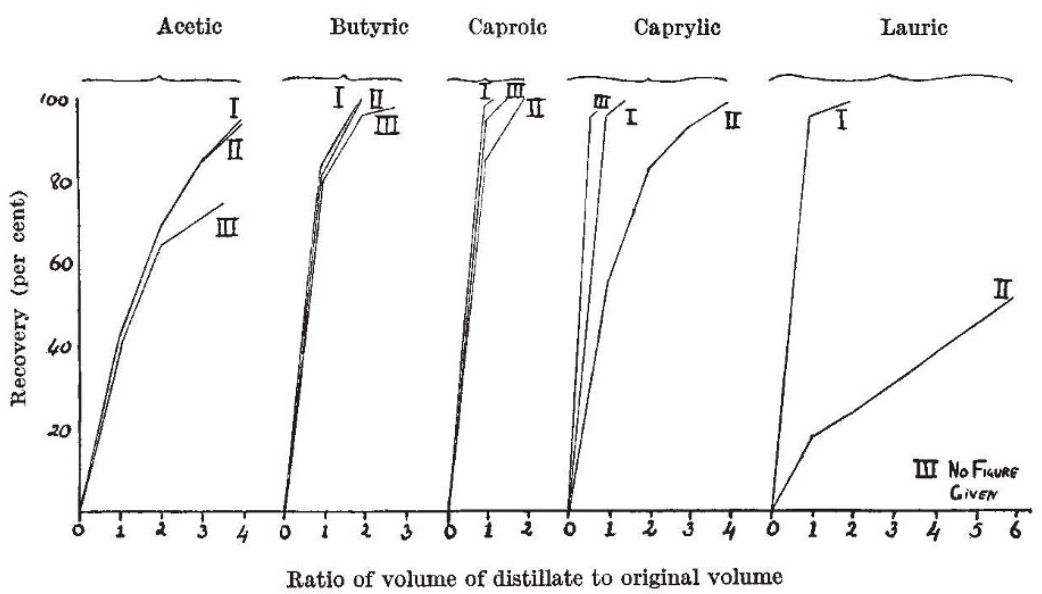

FIG. 1. Fatty acid recovery by steam distillation: I, acid distilled from distilled water; II, acid distilled from pure butter fat; III, distillation flgure given by Dyer.
The study of the rate of recovery of various volatile some of these acids by the butter fat, very marked

\section{The Stock of Antarctic Blue Whales}

Durreg the current investigations into the conditions of Southern whaling, I have had occasion to consult the publications ${ }^{1}$ of the Norwegian Whaling I3ureau, in which the catch statistics given in "International Whaling Statistics" have been amplified and to some extent analysed. From these data I have calculated the average length of female Blue whales taken from 1930 to 1935 . The results are shown in the following table.

$\begin{array}{ccc}\text { Season } & \text { No. of whales considered } & \text { Average length (ft.) } \\ 1930-31 & 4,532 & 82 \cdot 36 \\ 1931-32 & \text { close season } & \overrightarrow{81} \cdot 97 \\ 1932-33 & 5,285 & 81 \cdot 85 \\ 1933-34 & 6,487 & 79 \cdot 88\end{array}$

A slight annual decrease in length up to 1933-34 is followed by a sharp drop of nearly two feet in 1934-35. Blue females become sexually mature at about $78 \mathrm{ft}$., when they are approximately two years old. They arrive at maturity in the southern winter, and are found in the Antarctic the following summer with an average length of $80 \mathrm{ft}$. Pairing in July may result in pregnancy which lasts for ten months ${ }^{2}$.

Blue females taken in 1934-35 were, therefore, on the average, killed at the outset of their reproductive career. The consequences of continued intensive killing need scarcely be emphasized.

Average lengths were shown in the Norwegian publications, but the data had been divided, and average lengths were given for immature and adult whales

It was found, however, that although the rate of distillation of the higher acids was retarded by the presence of butter fat, almost complete recovery could be effected if the steam distillations were continued for a sufficiently long period. For the acids up to and including caprylic, more than 90 per cent of the added acid could be recovered by collecting a distillate of three times the original volume. For lauric acid, on the other hand, only 50 per cent was recovered even after collecting six times the original volume (cf. Fig. 1).

If the rate of distillation of these acids from a cheese mush is comparable with that from a mixture of butter fat and water, then the practice of collecting a distillate of three times the original volume would allow an estimate of the distribution of volatile acids in cheese which would be sufficiently accurate for many purposes. It is suspected, however, that a still greater retention occurs in the cheese mush, and the influence of cheese fat (as distinct from butter fat) and the protein and salt mixtures of cheese is being examined in an effort to elucidate this question.

\section{E. R. Hiscox.} J. Harrison.

National Institute for Research in Dairying, Shinfield, Nr. Reading, Berks.

$$
\text { May } 25 .
$$

${ }^{1}$ D. C. Dyer, J. Biol. Chem., 28, 445 (1916-17). separately. The constancy of the averages from season to season was invoked as evidence that undue depletion of the stock is not yet taking place, but since no account was taken of the rapidly mounting percentage of immature whales in the catch the results are liable to be misleading.

Alem H. Laurte.

"Discovery" Investigations,

52 Queen Anne's Chambers, London, S.W.1. June 3.

1 Hjort, Lie and Ruud, "Hvalrådets Skrifter", 3, 8, 9, 12. "Mackintosh and Wheeler, "Discovery Reports", I, pp. 468-9 (1929).

\section{The Manatee of St. Helena}

IN NATURE of March 17, 1934, p. 417, Prof. T. Mortensen quotes Dampier's reasons for refusing to believe in the existence of the sea-cow in St. Helena. The bibliography on the subject appears to be far from complete; but fortunately records by two eyewitnesses are available.

Probably the best account of the St. Helena manatee will be found in Barnes's "Tour of St. Helena" (Richardson, London, 1817, pp. 116 and 117), where a detailed description of the animal is quoted from the manuscript of Lieut. Thomas Leech, "written many years ago". The Leechs were a well-known and highly respectable Island family, and Thomas 